\title{
RETROFITTING PUBLIC TRANSPORT SYSTEMS TO REDUCE HEALTH HAZARDS FROM PANDEMICS
}

\author{
ROCKLEY G. BOOTHROYD \\ Chartered Engineer, Queensland, Australia
}

\begin{abstract}
The physical requirements of public transport systems are re-examined so that the influence of future virus pandemics can have minimal effects on public transport use. Rail, bus, tram and civil aviation are included. Previously suggested methods to increase usage of public urban transport are also included and reconsidered to help offset investment costs needed to provide security in future virus pandemics. It is also concluded that government controls to stimulate herd immunity should also include monitoring of the immune systems of populations in order to minimise adverse effects in future pandemics such as mutation of viruses.
\end{abstract}

Keywords: COVID-19, virus pandemic, public transport systems, human innate and adaptive immunity.

\section{INTRODUCTION}

The COVID-19 virus is at its most contagious within our big cities. It follows that it is mostly within the big city environment that we need to apply remedial measures. From the start the point must also be made that such virus pandemics are a natural control process of Nature. Predator/prey dynamics is the natural method of population control of any species where Nature perceives an imbalance in need of correction.

There are millions of different types of virus, based both on RNA and DNA genetics. Almost all viruses are benign in their effect on human life. Yet they all act as parasites on selected higher life-forms from the most humble of bacteria to ourselves. Having no reproduction systems like the higher forms of life which they invade, they reproduce by destroying cells in their host to use their chemicals in order to replicate themselves.

Despite the widespread belief that we should usually try to integrate ourselves with the forces of nature, the suggestion of changing our major cities to cope with disease is a very different matter of great concern to us. Our major cities are a vital part of our modern civilisation. Our cities host most of our high-level technologies on which we now depend. Also, cities need a very varied and highly skilled workforce to service these industries. In this respect it follows that we have no option but to find ways to accommodate high density human populations safely and adapt the raw forces of Nature and force them to meet our own specific needs.

\section{VIRUS PANDEMICS}

It is important to make good and long-lasting any investment in public transport systems. This raises the question of predicting the forms any future pandemics will take. This requires a good understanding of earlier pandemics and an understanding of the likely consequences of future mutations. At present our knowledge of COVID-19 is very limited and uncertain (see Appendices I and II). Fortunately, because cases of infection are now running into millions of victims we will, within a few months, be able, presumably, to analyse vast amount of statistical data (see Appendices I-III). This can be expected to answer many of our questions. This indicates that the present paper should only be considered as an interim report. 
It also seems logical that, when designing equipment to cope with pandemics, we should try to design "add on equipment" which can be removed easily and cheaply once the pandemic has run its course. The "add on equipment" can then be placed in store and hopefully be useful later when Nature inflicts the next pandemic on us. This is the policy adopted in the present interim paper. Future experience may well make this policy questionable.

\section{ADEQUATE SCIENTIFIC PRELIMINARY INVESTIGATIONS}

There are likely to be deficiencies in some of the statistical data mentioned above. In particular the state of a patient's immune system is seldom measured in medical practice in a detailed manner and an individual's immune systems can vary considerably even in persons of similar age [1].

\section{EXTREME PROBLEM AREAS}

Some of the areas of particular economic concern have factors which make it near impossible to come to conclusions at the present time. One such example is the heavily impacted cruise-ship tourist industry. This industry relies heavily on the social programmes of activity which are organised. The COVID-19 pandemic has to be recognised as a direct attack on any form of social activity. Such examples, which also include any form of public entertainment or education, are outside the scope of this paper.

\section{A VENTILATED FACIAL SHIELD}

Much has been written in the popular literature about the relative merits of the cloth face mask versus the transparent plastic facial shield used by many hospital workers. The mask gives only limited protection to the wearer, but its main value is to prevent larger droplets infecting other people nearby when the wearer coughs or sneezes. Larger droplets contain more virus than fine aerosol particles and consequently are likely to be far more dangerous. The fine aerosol particles obey Stokes law [2] where the aerodynamic restraining drag force on a fine aerosol particle makes them follow the surrounding air closely. These aerosol particles have much smaller cough/sneeze-projected trajectories than the 1arger droplets [2].

By contrast the hospital face shield also provides a shield against all droplets of any size and because the open base is quite wide, any upward air flow due to the wearer breathing is minimised allowing fewer fine aerosol particles to enter the wearer's lungs. We have all the technical information [3] we need to design this type of protective headgear. A final design for our purposes would be expected to look like that in Fig. 1. The approach illustrated in Fig. 1 seems likely to be used more frequently than other design concepts. This protective

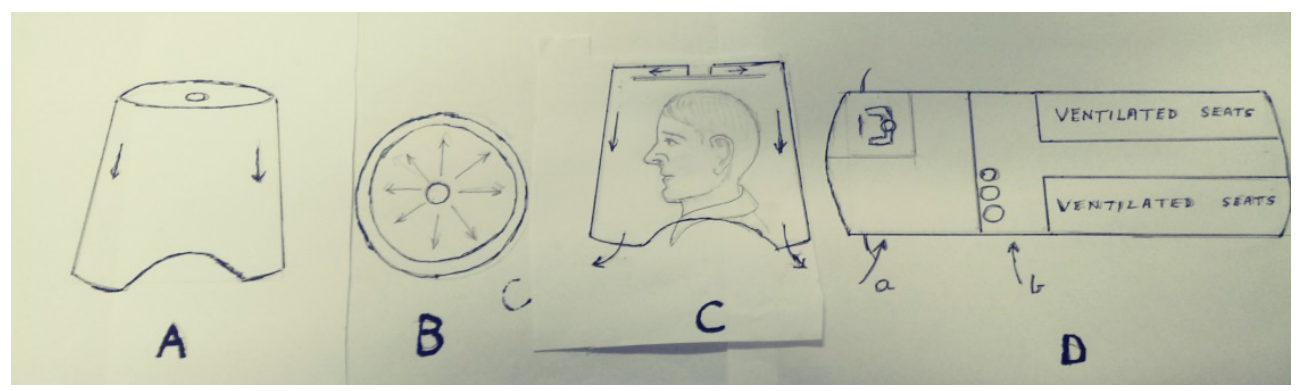

Figure 1: The most likely method of preventing virus infection in transport systems. 
unit shown in Fig. 1 is likely to become commonplace in future equipment and is in the form of a truncated circular cone shown at A. Its flat enclosing top (B) has a short central inside-facing socket. This can be connected with a catch-clip to a hose feeding uncontaminated air for the wearer. The lower edge of the catch-clip socket ends in a circular disc ((B) and (C)) projecting the incoming air to the inner edges of the helmet (C). This is to minimise turbulence and attain a smooth downflow of air which exits at the lower edge of the helmet. Two indentations on the lower edge allow the helmet to sit correctly on the wearer's shoulders.

\subsection{Application 1: Use in aircraft}

Most civil aircraft are fitted with overhead air supply points for each seated passenger. They are called gaspers. Gaspers could be replaced with short pull-down hoses which turn the air supply on when pulled and the free end can then be clipped to the helmet. Clean outside air is readily available at high altitudes and can be heated and bled from the engines to supply passengers with uncontaminated air. This air is finally exhausted from the aircraft at floor level. The physical nature whereby passengers become infected in aircraft is not well studied at the present time. Even young and fit cabin staff sometimes test positive for COVID-19. How this happens may be unclear. Today's air terminals are often grossly overcrowded and not organised well enough to control infection. Like many other workplaces they need special attention (Appendix IV).

\subsection{Application 2: Use in trains, trams and buses}

Because of their truncated cone shape, these helmets can be easily stacked in circular containers. Fig. 1(D) shows the passenger entrances for a suggested retrofitted local bus. This bus has two entrance/exit points for passengers. The entrance " $a$ " is for normal occasional passengers who pay the driver in the normal manner which is used today. These casual passengers are separated completely from those who enter at " $b$ ". These passengers entering at " $b$ " can only pass the entrance harrier by inserting their own personal public transport card. This card, normally used with a mobile phone, carries all the information of a previously booked seat in the virus-free section of the bus. This bus has three identical vertical cylinders at the "b" entrance. Each cylinder contains a pile of these helmets. Each of the three containers has three lights (let us say red, green and yellow). These indicator lights are located on all three lids, one of which is on the top of each container. When a bus (or tram or train) stops, the lid of the container with a yellow light opens and departing passengers place their discarded helmets in this bin. When the first new passenger inserts their travel "ID" card in the check slot in the bus outer wall, the yellow-lit cylinder lid closes and its yellow light changes to red. The lid of another cylinder (which displays a red light) then opens and it displays a green light. Each embarking passenger then uses a finger to lift out a helmet and takes his/her registered seat and couples up the helmet to the clean air system. The bus then departs and when it comes to the next stop, the cylinder with the red light changes to green. Cylinders which display a red light always have a closed lid while an ultra-violet (C) lighting system (see Section 8) sterilises the helmets for re-use.

\section{OFFSETTING RETROFITTING INVESTMENT COSTS IN PUBLIC TRANSPORT}

It is normal for traffic congestion in most cities to act as a stimulus for using the public transport alternative. Because of personal fear of infection by COVID-19, public transport 
use has usually been found to dwindle to an uneconomic level. The simultaneous implementation of lockdowns also reduced traffic congestion, but this is not really a desirable feature and is just a consequence of the world economy taking a staggering blow.

By far the most important factor is that public transport systems are also usually underutilised, even in normal times. This is because most people live at an inconveniently long distance from the nearest bus stop or train station.

As the danger of further pandemics is placing public transport in the unenviable position of becoming unviable, it is appropriate to also reconsider an earlier study [4] which was aimed at developing a much-increased patronage of our existing public transport. The argument is that, if a time has now come to redesign public transport for health reasons, then it is reasonable to combine these measures with a program to make public transport much larger and with a stronger financial basis.

\section{AN EARLIER RELEVANT STUDY}

Fig. 2 shows a composite view of this earlier work [4]. View A shows a man leaving home to go to work. He is pulling a small case on 2 large wheels. The case is rather like the suitcases we normally use when traveling. He then unlatches the suitcase when he reaches the road to reveal a $20 \mathrm{~kg}$ folded motor scooter shown at B. This is easily unfolded in a few seconds and locking sliding-tube joints produce a lightweight motor scooter shown at $\mathrm{C}$. He then travels at a maximum speed of $20 \mathrm{~km} / \mathrm{hr}$ along bicycle tracks to a bus stop or railway station where the scooter is folded up and placed in its case. At D, he is stowing his scooter in a numbered locker in an express train. If he was catching a slow speed bus, his personal transport would be attached to a numbered hook system on the outer side of the bus. When he gets to his destination he unfolds his scooter and rides to work. All the ticketing/reservation for this system would normally be done on the ubiquitous mobile phone with a system access card for using public transport. Today government authorities would have the right to control use of the card if the holder is suspected of carrying an infection. For example, the virus vaccination details would be recorded on the id card and would control the card's use.

Fig. 2 shows activity in a warm climate with a scooter using a $1 \mathrm{~kW}$ lithium-ion energised motor with a battery which is rechargeable on public transport. Recharging costs would be added to the user's card. In colder climates such as winter in Helsinki or Toronto, a similar system was suggested using a miniature air-cooled diesel engine which can also provide up to $400 \mathrm{~W}$ of riding suit heating through a thermostatically controlled umbilical cord.

It was also envisaged that secondary school children would be allowed to ride these scooters to and from school. Users of this system may prefer to use their own pushbike style headgear which would include and be designed to be compatible with the head shield described in Fig. 1.

\section{DISCUSSION}

Combating COVID-19 and other pathogens which can cause pandemics goes a long way beyond the limited scope of this paper. For example, we have experienced outbreaks of COVID-19 in large commercial organisations such as abattoirs.

In order to safeguard staff, any large company may well decide to install disinfection equipment. One commonly available form for treating air supplies is to use ultra-violet (C) lighting which sterilises viruses [5]. This could be a system which takes only a portion of the output of an air conditioner. Because UV (C) light is harmful to human skin, causing 


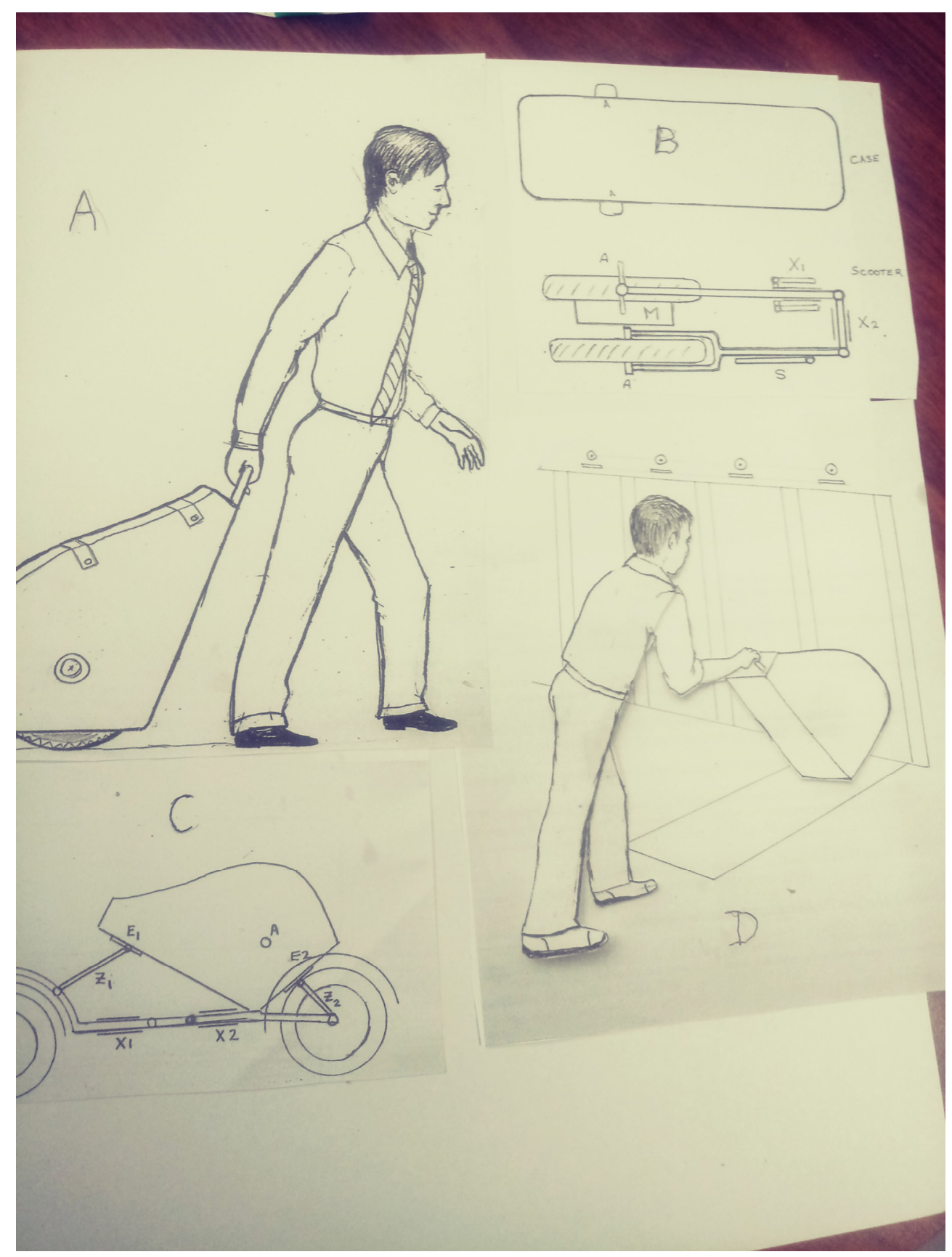

Figure 2: Summary of earlier work to improve public transport economic viability [4].

the onset of melanoma and other cancers, this form of sterilisation must take place in a closed container. Inadvertently such a process also produces dead pathogens which, in a small way, are beneficial to employees. Such a company, acting responsibly, would 
probably also install equipment for visual recording and identification of staff. This is to monitor and provide warning of abnormal coughing, sneezing and high skin temperature. Facial recognition technology, as widely used today in China, is now available and can be adapted easily to request anyone suspected of infection to report immediately to the appropriate authority.

It is reasonable that any organisation employing staff should be able to exercise the same rights as governments assume when ordering compulsory cessation of activity which is suspected as dangerous to public health. Because RNA based viruses are prone to random mutation, it is difficult to prescribe industrial codes of practice as an alternative precautionary measure.

The above suggestions are not new technology. Sensitive areas in hospitals such as operating theatres are often sterilised overnight with UV-C radiation when not in use. Statistical information, such as immune system cell counts from theatre staff would be of much interest in improving virus control.

Vaccines made from dead or weakened viruses are likely to be very effective. To the best of the present writer's knowledge, no vaccine manufacturer has attempted to use this approach due to lack of basic knowledge concerning the dangers of COVID-19. For example, the much-used AstraZeneca vaccine uses a harmless vector virus to transfer artificially processed genetic material into our cells to trick our immune system to respond. This, like other vaccines using new technologies may, or may not, take place correctly in different individuals.

\section{OUR IMMUNE SYSTEM: A NEGLECTED AREA OF HUMAN HEALTH?}

Our artificial armoury against the ravages of COVID-19 viz. lockdown, hand washing, masks, vaccines and social distancing, are only supplementary. Our normal defence against pathogens is our own immune system [6]. One might even suggest that some of the mysteries surrounding COVID-19 may even be explainable in terms of immune system behaviour if we had more accurate facts at our disposal.

Government instrumentalities worldwide seem to have ignored the importance of a healthy immune system. A most useful recent book [7] has raised this issue. This book has also drawn attention to the likely importance of deficiencies in selenium, zinc and vitamins $\mathrm{C}$ and D [7, pp. 37-70]. The question needs to be posed: "are immune system deficiencies the cause of the wide spectrum of COVID-19 symptoms?"

It is normal for our immune systems to decline with advancing age and a blood test and cell count analysis are available for us all from routine pathology.

In short, all this explains why any artificial interference in the inner workings of our immune system such as using vaccination or drugs must be undertaken with great care. Mammalian immune systems are believed to be the first natural biological control system to develop. Also, the complexity of our human immune system is second only to that of the human brain. At the present time, it is preferable to only stimulate our immunity externally that is by vaccination. Present approved vaccination is by new and indirect safer methods of moving immune-stimulating genetic material into our cells.

In immunology, although our immunity is a single system, it is normally considered as 2 parts. The innate system is fast acting and not specialised in defending against any specific pathogen attack. The second defence line of the system is our adaptive immune system which has advanced memory cells which act additionally from experience of previous infections. This second system is slower to respond but gives the extra boost needed in severe illness. 
Through genetic mutation, pathogens try to find ways past our immunity. If our complicated immune system is overstressed, it does not work as efficiently, and adverse effects occur (see literature on excess inflammation and cytokine storms which can have fatal effects). It has been suggested [6] that the fast-acting innate part of our immune system may also have some memory capacity for past infections and presumably this could improve the effectiveness of our new vaccines.

Vaccination is the method of prime interest in stimulating immunity but there is another much neglected method of strengthening our defences. This is to optimise our immune systems such as by diet and other lifestyle methods [7, pp. 40-147]. We also suffer from many autoimmune diseases from immune systems which are oversensitive. Some infections cause immune system overload and inflammation can be so severe as to be fatal (see literature on cytokine storms).

Fortunately, we are also able to disadvantage virus pathogens by altering their environment adversely with engineered devices as described in the present paper.

\section{CONCLUSIONS}

1. Our basic understanding of COVID-19 is inadequate. Much has yet to be explained.

2. A comprehensive statistical analysis of past patients (both living and dead) is essential if we are to be able to cope with future pandemics.

3. Future pandemics are likely to involve the human respiratory system as the main source of infection. This makes retrofitting an economically feasible solution in reengineering our public transport systems.

4. A policy of "add on" technology to existing public transport systems is a feasible approach in many cases.

5. Following on from item 4 above, the ventilated face shield seems to be the most useful and versatile form of protection available to us.

6. In order to offset the costs of retrofitting to upgrade protection of public health, it is recommended that simultaneously steps are taken to enlarge the patronage of public transport.

7. Consideration of immune system deficiency seems to be a neglected area of interest in offsetting future problems.

8. It is logical to plan relief from future pandemics by giving more attention to item 7 .

9. Re-engineered systems can assist in controlling virus pandemics. At present progress is limited by lack of reliable basic data. Good design depends on hard facts.

\section{APPENDIX 1: TRANSMISSION OF COVID-19}

Evolution has given the human species a remarkably effective innate immune system to provide us with a very fast-operating first defence line against invading pathogens. Our skin is a major component of this. Unfortunately, we need orifices in our skin and pathogens, also exploiting the creativity of evolution, have learnt how to use these orifices to invade our bodies. A number of scientists have suggested that our throat/nose/mouth area is a particularly weak area, despite the development of its own local immune system, and is perhaps even an example of poor design compromise from the evolutionary powers of optimisation. As an intelligent species perhaps we can outwit future virus pandemics by 
guessing accurately that the unintelligent virus will always try first to exploit the mouth/nose/throat orifice?

\section{APPENDIX II: SURVIVAL AND VIABILITY OF COVID-19}

A few leading journals such as the Lancet and New England Journal of Medicine have reported preliminary data concerning the survival of COVID-19 virus on various surfaces. This virus can survive for several days on cleanable smooth surfaces like glass, metal and plastic whereas survival on cloth and paper is much shorter and measured in hours. Unfortunately, these presently available data are insufficient for the design of engineered equipment for use in a virus-contaminated environment.

U.S. Department of Homeland Security [8] suggest that ordinary sunlight kills off most of the virus which now contaminates our world, but we need much more precise information for design purposes. For example, for the bus shown in Fig. 1(D), should the inlet air for the ventilated facial shields be drawn in from the top of the vehicle and spent air vented beneath the vehicle? Would this be adequate for a bus when it is in an underground city centre bus terminal or should this terminal use a specially designed and adapted air conditioning system? Many reports [9], [10] are comprehensive within their stated limits but are not applicable to the inner city virus contamination we face [11]-[13].

\section{APPENDIX III: AREAS OF UNCERTAINTY IN OUR KNOWLEDGE OF COVID-19}

These have been well tabulated in the literature. Just two examples are:

- Why do infected people vary so much in the symptoms they display?

- Why do infected people vary so much regarding recovery time and why do some patients suffer "long COVID-19"?

We need to know why and how these differences occur.

Pathologists seem to have made significant contributions [14], [15] perhaps because, by the nature of their work, they may have escaped much of the trauma experienced by medical colleagues struggling in the hospital wards. Yet in order to interpret pathology data to the best effect we also need good records obtained in the hospital wards for the same patients, be they alive or dead. Perhaps this is often too much of an expectation? Brazil has been so hard pressed that there has hardly been time and space to bury their dead. At the time of writing, the experience in India has been nothing less than horrific.

\section{APPENDIX IV: THE FUTURE OF THE AVIATION INDUSTRY}

It seems that the confined passenger seating of tourist class passengers can probably be preserved. Cheap airfares will simply have to disappear if social distancing becomes necessary in airliners. There are many alternative options.

Much depends on the success of the world vaccination programme. Studies of virus infection in civil aircraft are limited and need to be more detailed. Airport terminals are not designed for virus pandemics and seem likely to be much of the problem. Alteration of flight schedules may help. Perhaps long-distance 14 hour fast flights can be replaced by shorter hops of 7 hours or so with passengers marshalled as an isolated group into hotels at night with a full-sized breakfast and evening meal in the hotel. In this way only light refreshments at midday, need be issued in rows to minimise infection. Cost estimates and all these aspects and alternatives are a matter for investigation by the airlines. 


\section{APPENDIX V: ORIGINS OF THE PRESENT PAPER}

In an earlier paper [16] the present author investigated the following matter.

The hydrogen atom, i.e. a proton, remains stable for at least $10^{24}$ years whereas a free neutron decays into a proton with a half-life of only a few minutes. Yet both comprise three "up" and "down" quarks (in the ratio two up/one down and one up/two down respectively). These quarks are by themselves extremely unstable and cannot be isolated for detailed examination. Moreover if a free neutron enters an atom's nucleus, which is a common event (and usually easy to accomplish) it can often increase or decrease the stability of the invaded nucleus markedly.

By way of explanation it was suggested that a self-repair mechanism seems to exist in physical matter and this also had some interesting consequences such as explaining the forward arrow of time. These matters are compatible with our observed experience.

Our present understanding of physical science is that it lacks any real creative ability in itself. Yet the very opposite is true in the biological sciences where the act of creation is commonplace. Also, in DNA based life, self-repair [17] of damaged genetic material is also prevalent and very sophisticated compared with the present author's study [16]. Today this genetic repair technology is also carried out by ourselves [18].

Therefore it was not unexpected that evolutionary forces would have developed a highly sophisticated self-repair system in living species. Consequently, it was natural enough for the present author to take an interest in biology and especially in the human immune system where the science of self-repair is so advanced and sophisticated [17]. The best way to enter into this new, large and complicated branch of science was to first examine Wikipedia documents. These are concise, very readable and most important of all, edited vigorously to exclude uncertain or speculative science. In this way the present author was able to progress to many detailed papers. Just a few are mentioned here as examples. This handful of many other references [19]-[32] was found useful in this last study, even if much of immunology is still not well understood.

All this concludes the present author's study of three very different systems ( $a, b$ and $c)$ which share the same properties viz:

- The basic inner components of the system have high levels of communication (signalling) between the component parts.

- These components have a strong awareness of "self" and ability to recognise differences from their own "self".

The studies were for:

(a) The self-testing and repair computers which are commonly used in deep space missions. This system is entirely a product of human ingenuity and is based on wellunderstood mathematics of probability.

(b) The proton which is a component of all matter in our known Universe. Dismissing any consideration of an explanation of the mystery surrounding the existence of any matter in our Universe, it is possible to explain how the expected lifespan of a proton is of the order of $10^{24}$ years [19].

(c) The final study is by far the most advanced and sophisticated system, namely the human immune system. This is also the only system known to the present author which also encompasses the ability to produce new life-forms. It includes the basis of the evolutionary development of new life, i.e., in this present day, it is the origin of creation itself. 


\section{REFERENCES}

[1] Lawton, G., You're only as young as your immune system. New Scientist, 245(3275), pp. 44-48, 2020.

[2] Streeter, V.L., Fluid Mechanics, 5th ed., McGraw Hill: New York. pp. 271, fig. 5.21, 1961.

[3] Davies, C.N. (ed.), Aerosol Science, Academic Press: New York, 1966.

[4] Boothroyd, R.G., Replacing the private motor car with a more attractive public transport system. 12th World Conference on Transport Research, Lisbon, Portugal, 11-15 July, Paper 1061, 2010.

[5] Harnzavi, I.H. et al., Ultraviolet germicidal irradiation: Possible method for respirator disinfection to facilitate reuse during the COVID-19 pandemic. Journal of the American Academy of Dermatology, 82(6), pp. 1511-1512, 2020.

DOI: 10.1016/jaad.2020.03.085.

[6] Lawton, G., Your first line of defence. New Scientist, 250(3328), pp. 40-44, 2021.

[7] Cabot, S., Corona and other Dangerous Viruses, SCB Inc.: Glendale, AZ, 2020.

[8] U.S. Department of Homeland Security, How does the environment impact COVID19? https://www.dhs.gov/science-and-technology/news/2020/10/29/feature-articlehow-does-environment-impact-COVID-19.

[9] Lin, K. \& Marr, L.C., Humidity dependent decay of viruses, but not bacteria, in aerosols and droplets follows disinfection kinetics. Environmental Science and Technology, 54(2), pp. 1024-1032, 2020. DOI: 10.1021/acs.est.9b04959.

[10] Parliente, N., Sierra, S., Lowenstein, P.R. \& Domingo, E., Efficient virus extinction by combinations of a mutagen and antiviral inhibitors. Journal of Virology, 75(20), pp. 9723-9730, 2001. DOI: 10.1128/jv1.7520.9723-9730.2001.

[11] Tang, J.W., The effect of environmental parameters on the survival of airborne infectious agents. Journal of the Royal Society Interface, 6(suppl. 6), pp. s737-s746, 2009. DOI: 10.1098/rsif.2009.0227.focus.

[12] Doremalen, N. et al., Aerosol and surface stability of SARS-CoV-2 as compared with SARS-CoV-1. New England Journal of Medicine, 382, pp. 1564-1567, 2020. DOI: $10.1056 /$ nejm c 2004973.

[13] Goodman, J.R., An evolving crisis. New Scientist, 246(3283), 2020.

[14] Carsana, L. et al., Pulmonary post-mortem findings in a series of COVID-19 cases from northern Italy: A two-centre descriptive study. Lancet Infectious Diseases, 20(10), pp. 1135-1140, 2020. DOI: 10.1065/s1473-3089(20)304334-5.

[15] Hanley, B. et al., Histopathological findings and viral tropism in UK patients with severe fatal COVID-19: A post mortem study. The Lancet Microbe, 1(6), pp. e245e253, 2020. DOI: 10.1016/s2666-5247(20)30115-4.

[16] Boothroyd, R.G., Fundamental energy physics and planet earth's platform for life. International Journal of Design and Nature and Ecodynamics, 15(2), pp. 135-143, 2020. DOI: $10.18280 /$ ijdne.150201.

[17] Ronen, A. \& Gluckman, B.W., Human DNA repair genes. Environmental and Molecular Mutagenesis, 37(3), pp. 41-83, 2001. DOI: 10.1002/em.1033.

[18] Men, K., Duan, X., He, Z., Yang, Y., Yao, S. \& Yuquan, W., CRISPR/Cas 9mediated correction of human genetic disease. China Life Sciences, 60(5), pp. 447457, 2017. DOI: 10.1007/s11427-017-9032-4.

[19] Wilczec, F., The Lightness of Being: Big Questions Real Answers, Penguin: London, pp. 1-270, 2008. 
[20] Akira, S. \& Hemmi, H., Recognition of pathogen-associated molecular patterns by TLR family. Immunology Letters, 85(2), pp. 85-95, 2003.

DOI: 10.1016/s-0165-2478(02)00228-6.

[21] Danemann, R. \& Prat, A., The blood-brain barrier. Cold Spring Harbor Perspectives in Biology, 7(1), a020412, 2015. DOI: 10.1101/cshperspect.a020412.

[22] Ljunggren, H.G. \& Karree, K., In search of the "missing self": MHC molecules and NK cell recognition. Immunology Today, 11(7), pp. 237-244, 1990.

DOI: 10.1016/0167-5699(90)90097-s.

[23] Eggenhuizen, P.J., Ng, B.H. \& Ooi, J.D., Treg enhancing therapies to treat autoimmune diseases. International Journal of Molecular Sciences, 21(19), 2020. DOI: $10.3390 /$ ijms 21197015.

[24] Limaye, S., Tests for cell-mediated immunity. Australian Prescriber, 33, pp. 84-87, 2010. DOI: 10.18773/austprescr.2010.041.

[25] Rus, H., Cudrici, C. \& Niculescu, F., The role of the complement system in innate immunity. Immunology Research, 33(2), pp. 103-112, 2005. DOI: 10.1385/IR:33:2:103.

[26] Sarma, J.V. \& Ward, P.A., The complement system. Cell Tissue Research, 43(1) pp. 227-235, 2011. DOI: 10.1007/s00441-010-1034-0.

[27] Fang, S., Wang, H., Lu, L., Jia, V. \& Xia, Z., Decreased complement C3 levels are associated with poor prognosis in patients with COVID-19: A retrospective cohort study. International Immunopharmacology, 89(part A) 107070, 2020.

DOI: 10.1016/j.intmp.2020.107070.

[28] Wong, R. \& Bhattacharya, D., Basics of memory B-cell responses: lessons from and for the real world. Immunology, 156(2), 2018. DOI: 10.1111/Imm.13019.

[29] Fenton, A., Lello, J. \& Bonsall, M.B., Pathogen responses to host immunity: the impact of time delays and memory on the evolution of virulence. Proceedings of the Royal Society B, Biological Sciences, 273(1597), pp. 2083-2090, 2006.

DOI: $10.1098 / \mathrm{rspb} 20063552$.

[30] Vivier, E., Tomassello, E., Baratin, M., Waltzer, T. \& Ugolini, S., Functions of natural killer cells. Nature Immunology, 9, pp. 503-510, 2008.

[31] Dantzer, R., Neuroimmune interactions: from the brain to the immune system and vice versa. Physiological Reviews, 98(1), pp. 477-504, 2018. DOI: 10.1152/physrev.00039.2018.

[32] Taams, L.T., Neuroimmune interactions: how the nervous and immune systems influence each other. Clinical and Experimental Immunology, 197, pp. 276-277, 2019. DOI: $10.1113 /$ cei.13355. 